\title{
Pengaruh Suhu Karbonisasi dan Variasi Kecepatan Udara Terhadap Laju Pembakaran Briket Campuran
}

\author{
Riska Tri Handayani ${ }^{1}{ }^{*}$, Sri Suryaningsih ${ }^{2}$ \\ ${ }^{1}$ Program Studi Fisika, Universitas Padjadjaran, Jl. Raya Bandung-Sumedang KM 2, Jatinangor \\ Sumedang 45363 \\ ${ }^{2}$ Laboratorium Fisika Energi, Universitas Padjadjaran, Jl. Raya Bandung-Sumedang KM 2, \\ Jatinangor Sumedang 45363
}

* Penulis Penanggungjawab. E-mail: handayaniriska762@gmail.com

\begin{abstract}
ABSTRAK
Biomassa dapat dimanfaatkan menjadi energi alternatif sebagai bahan bakar dalam bentuk briket yang mengandung unsur utama atom karbon (C) yang berasal dari kandungan selulosa, hemiselulosa dan lignin. Karakteristik briket dapat dilihat dari beberapa hal diantaranya suhu karbonisasi dan kecepatan udara yang berpengaruh terhadap laju pembakaran briket, sehingga tujuan penelitian ini adalah mengetahui suhu karbonisasi dan variasi kecepatan udara terhadap laju pembakaran briket campuran sekam padi dan tongkol jagung. Tahapan pembuatan briket dengan cara pengeringan bahan, karbonisasi pada suhu $200^{\circ} \mathrm{C}, 225^{\circ} \mathrm{C}, 250^{\circ} \mathrm{C}, 275^{\circ} \mathrm{C}$, penghalusan dan penyaringan bahan dengan ukuran butir 40 mesh, pencetakan briket dengan konsentrasi pencampuran sekam padi dan tongkol jagung 50:50, dan pengeringan briket. Pengujian nyala briket dilakukan dengan variasi kecepatan udara $0,8 \mathrm{~m} / \mathrm{s}, 1,1 \mathrm{~m} / \mathrm{s}, 1,2 \mathrm{~m} / \mathrm{s}, 1,3 \mathrm{~m} / \mathrm{s}, 1,4 \mathrm{~m} / \mathrm{s}$. Hasil penelitian menunjukan briket yang dibuat dengan suhu karbonisasi yang tinggi maka laju pembakaran semakin lambat karena semakin rendahnya zat volatile matter dengan laju pembakaran 0,46 gr/menit pada suhu karbonisasi $225^{\circ} \mathrm{C}$ dengan $\mathrm{v}=1,4 \mathrm{~m} / \mathrm{s}$. Dan semakin besar kecepatan udara maka laju pembakaran akan semakin kecil karena panas temperatur akan ikut terbuang dengan semakin besarnya kecepatan udara, dengan laju pembakaran optimum $0,42 \mathrm{gr} /$ menit dengan kecepatan udara $1,4 \mathrm{~m} / \mathrm{s}$ pada briket suhu karbonisasi $225^{\circ} \mathrm{C}$.
\end{abstract}

Kata Kunci : Briket, Karbonisasi, Kecepatan Udara, Laju Pembakaran, Sekam Padi 


\begin{abstract}
Biomass can be utilized as an alternative energy as fuel. Biomass contains the main elements of carbon atoms $(\mathrm{C})$ derived from the content of cellulose, hemicellulose and lignin. Characteristics of briquettes can be seen from several things incluiding the carbonization temperature and air velocity affect the burning rate of briquettes, so the purpose of this research is to know the effect of carbonization temperature and air speed variation of the burning rate briquette mixture of rice husks and corn cobs. The research methodology includes material drying, carbonization at $200^{\circ} \mathrm{C}$, $225^{\circ} \mathrm{C}, 250^{\circ} \mathrm{C}, 275^{\circ} \mathrm{C}$, refining and filtering of 40 mesh materials, briquette printing and pressing with concentration of material mixing rice husks and corn cobs 50:50, and briquette drying. Further testing of flame briquettes with air velocity $0,8 \mathrm{~m} / \mathrm{s}, 1,1 \mathrm{~m} / \mathrm{s}, 1,2 \mathrm{~m} / \mathrm{s}, 1,3 \mathrm{~m} / \mathrm{s}$ and $1,4 \mathrm{~m} / \mathrm{s}$. The results showed the briquettes are made by high carbonization temperature then the slower burning rate because of the low volatile matter with burning rate $0,46 \mathrm{gr} /$ menit on carbonization temperature $225^{\circ} \mathrm{C}$ with air speed $1,4 \mathrm{~m} / \mathrm{s}$. The greater the air velocity, burning rate will be smaller because temperature heat will be wasted along with increasing air speed and optimum burning rate $0,42 \mathrm{gr} /$ menit was found on speed $1,4 \mathrm{~m} / \mathrm{s}$ with carbonization temperature briquettes $225^{\circ} \mathrm{C}$
\end{abstract}

Keywords : Briquette, Carbonization, Air Velocity, Burning rate, Rice Husks.

\section{Pendahuluan}

Tingkat konsumsi energi fosil untuk sektor rumah tangga dan industri menurut kementrian ESDM 2013 semakin meningkat dari tahun 20032013[1]. Dengan meningkatnya konsumsi energi fosil menyebabkan ketersediaan energi fosil semakin menurun karena energi fosil adalah salah satu energi yang tidak terbarukan dan ketersediannya terbatas. Dalam mengatasi hal tersebut, dibutuhkan suatu energi alternatif pengganti bahan bakar fosil yaitu dengan memanfaatkan biomassa sebagai bahan bakar dalam bentuk briket. Briket merupakan gumpalan arang yang memiliki nilai kalor yang tinggi dengan membakar bahan biomassa kering tanpa udara atau dikenal dengan karbonisasi[2]. Tanaman penghasil energi yang dapat dijadikan sebagai bahan baku briket adalah sekam padi dan tongkol jagung. Sekam padi yang sudah dijadikan briket hanya memiliki nilai kalor 3330,45 kal/gram[3] sehingga dibutuhkan penambahan bahan 
lain untuk meningkatkan nilai kalor briket sekam padi yaitu dengan penambahan tongkol jagung yang memiliki nilai kalor $4451 \mathrm{kal} / \mathrm{gram}[4]$. Kualitas briket tidak hanya dilihat dari bahan bakunya saja tetapi dipengaruhi oleh beberapa hal yaitu suhu karbonisasi dalam menguraikan karbon yang terkandung pada selulosa, hemi selulosa dan lignin yang akan berpengaruh pada nilai kalor yang dihasilkan. Sebagai bahan bakar, briket harus memiliki laju pembakaran yang baik. Laju pembakaran dipengaruhi oleh kecepatan udara yang berpengaruh terhadap pencapaian temperatur pembakaran maksimum dan lamanya pembakaran. Adapun tujuan dari penelitian ini adalah :

1. Mengetahui pengaruh suhu karbonisasi terhadap laju pembakaran briket campuran sekam padi dan tongkol jagung

2. Mengetahui pengaruh kecepatan udara terhadap laju pembakaran briket campuran sekam padi dan tongkol jagung

\section{Metode Penelitian}

\subsection{Alat dan Bahan}

Alat yang digunakan adalah termokopel, anemometer, furnace, drum karbonisasi, blender, saringan 40 mesh, oven, neraca analitik, kalorimeter bomb, stopwatch dan kompor briket. Serta bahan yang digunakan adalah sekam padi, tongkol jagung, tepung tapioka dan air.

\subsection{Prosedur Penelitian}

Sekam padi dan tongkol jagung dikeringkan dengan panas sinar matahari selama 1 hari (5jam). Bahan yang telah kering dikarbonisasi pada tungku pembakaran(drum) dengan suhu $200^{\circ} \mathrm{c}, \quad 225^{\circ} \mathrm{c}, \quad 250^{\circ} \mathrm{c}, \quad 275^{\circ} \mathrm{C}$ selama 100-150 menit untuk sekam padi dan karbonisasi pada furnace dengan suhu $200^{\circ} \mathrm{c}, 225^{\circ} \mathrm{c}, 250^{\circ} \mathrm{c}, 275^{\circ}$ $\mathrm{C}$ selama 2 jam untuk tongkol jagung. Selanjutnya proses penghalusan sampel dan penyaringan untuk menentukan ukuran butir sampel dengan menggunakan saringan 40 mesh.

Proses pencampuran bahan dengan presentase perbandingan 50:50 dengan perekat $6 \%$ dan air 1:10 ml. Briket dicetak dengan alat cetak hidrolik pada tekanan 4,6 Psi. Setelah proses pencetakan, briket dikeringkan dengan sinar matahari selama 8 jam dan oven pada $50^{\circ} \mathrm{C}$ selama 270 menit. Pengujian karakteristik briket dengan metode ASTM D 3173-03(uji kadar air), ASTM D 3174-04(uji kadar abu), ASTM D 3175(E) (uji kadar volatile matter), ASTM D 5865-04 (uji nilai kalor)[5]. Pengujian nyala briket dilakukan dengan kompor briket pada kecepatan udara $0,8 \mathrm{~m} / \mathrm{s}, 1,1 \mathrm{~mm} / \mathrm{s}, 1,2$ $\mathrm{m} / \mathrm{s}, 1,3 \mathrm{~m} / \mathrm{s}$, dan $1,4 \mathrm{~m} / \mathrm{s}$. Selama proses pembakaran briket diamati suhu pada interval waktu 3 menit hingga briket habis terbakar. Sebelum dan 
setelah dilakukan pembakaran briket ditimbang untuk mengetahui laju pembakaran briket.

\section{Hasil dan Pembahasan}

Pengujian karakteristik dilakukan untuk mengetahui sifat briket. Karakteristik meliputi kadar air, kadar abu, kadar volatile matter, fixed carbon dan nilai kalor.

Tabel 1. Hasil pengujian karakteristik briket campuran sekam padi dan tongkol jagung.

\begin{tabular}{cccccc}
\hline $\begin{array}{c}\text { Suhu } \\
\left({ }^{\mathbf{0}} \mathbf{C}\right)\end{array}$ & $\begin{array}{c}\text { Kadar } \\
\text { Air (\%) }\end{array}$ & $\begin{array}{c}\text { Kadar } \\
\mathbf{A b u} \\
\mathbf{( \% )}\end{array}$ & $\begin{array}{c}\text { Volatile } \\
\text { Matter } \\
(\mathbf{\%})\end{array}$ & $\begin{array}{c}\text { Vixed } \\
\text { Carbon } \\
(\%)\end{array}$ & $\begin{array}{c}\text { NIlai } \\
\text { Kalor } \\
(\%)\end{array}$ \\
\hline 200 & 8,10 & 26,09 & 16,21 & 49,60 & 4728 \\
\hline 225 & 8,18 & 26,30 & 15,54 & 49,98 & 4687 \\
\hline 250 & 8,36 & 26,22 & 12,92 & 52,50 & 4743 \\
\hline 275 & 9,49 & 29,48 & 12,78 & 48,52 & 4353 \\
\hline
\end{tabular}

Karbonisasi merupakan proses pelepasan karbon pada selulosa, hemiselulosa dan lignin pada biomassa untuk memperoleh nilai kalor yang tinggi sebagai bahan bakar.

Pada pengujian kadar air bahwa dengan semakin meningkatnya suhu karbonisasi maka kadar air yang terkandung pada briket semakin besar. Seharusnya semakin meningkat suhu karbonisasi, kadar air yang terkandung pada briket semakin kecil dikarenakan air dalam bentuk moisture akan lebih banyak menguap ketika suhu karbonisasi dinaikkan dari suhu $200^{\circ} \mathrm{C}$ sampai $275^{\circ} \mathrm{C}[6]$.

Pada pengujian kadar abu bahwa dengan semakin meningkatnya suhu karbonisasi maka kadar abu yang terkandung pada briket akan semakin besar karena bahan akan banyak terbakar dan menyisakan abu. Kadar abu tertinggi berada pada briket suhu karbonisasi 275 ${ }^{\circ} \mathrm{C}$ sebesar 29,48\%. Abu merupakan material yang tidak dapat menguap ketika dipanaskan pada suhu tinggi.

Volatile matter adalah zat yang mudah menguap ketika dipanaskan pada suhu tinggi dengan melibatkan oksigen yang terbatas atau dikenal dengan karbonisasi[6]. Gas yang terkandung pada volatile matter diantaranya gas hidrokarbon, metana, dan karbon monoksida. Dengan semakin meningkatnya suhu karbonisasi, kadar volatile matter yang terkandung pada briket semakin kecil disebabkan karena dengan semakin besarnya suhu karbonisasi maka akan lebih banyak zat yang mudah menguap sehingga kandungan volatile matter pada briket semakin kecil. Kadar volatile matter terkecil pada suhu karbonisasi $275^{\circ} \mathrm{C}$ yaitu $12,78 \%$. Tingginya volatile matter dapat mempermudah dalam proses pembakaran briket.

Kadar fixed carbon diperoleh dari pengurangan presentase $100 \%$ dengan penjumlahan kadar air, kadar abu dan volatile matter. Briket dengan suhu $250^{\circ}$ C memiliki karbon terikat yang besar yaitu $52,5 \%$ dan briket dengan suhu $275^{\circ}$ $\mathrm{C}$ memiliki karbon terikat terendah yaitu 
48,52\% karena memiliki kandungan abu yang lebih tinggi.

Nilai kalor maksimum adalah $4743 \mathrm{kal} /$ gr pada briket dengan suhu karbonisasi $250^{\circ} \mathrm{C}$ karena kandungan karbon terikatnya yang besar. Kadar karbon terikat dan karakteristik briket yang lain dapat berpengaruh terhadap nilai kalor yang dihasilkan.

Pengaruh suhu karbonisasi dan kecepatan udara terhadap laju pembakaran briket campuran sekam padi dan tongkol jagung.

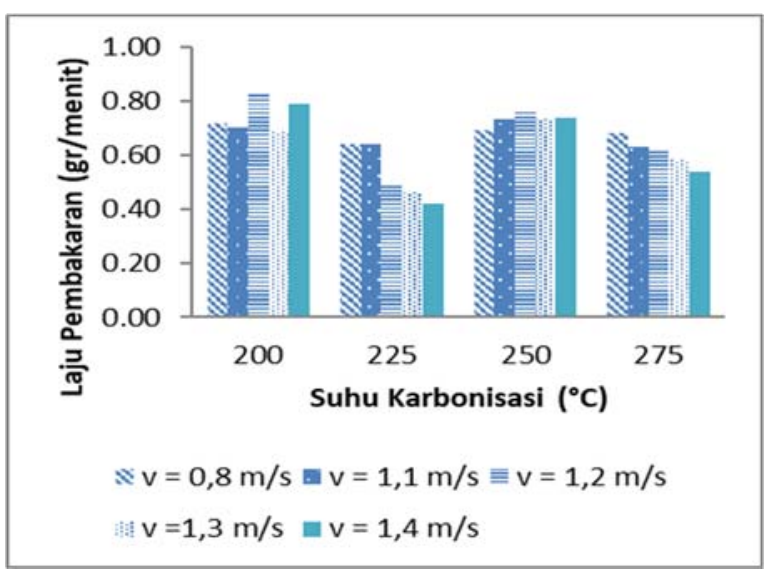

Gambar 1. Pengaruh suhu karbonisasi terhadap laju pembakaran briket untuk setiap variasi kecepatan udara

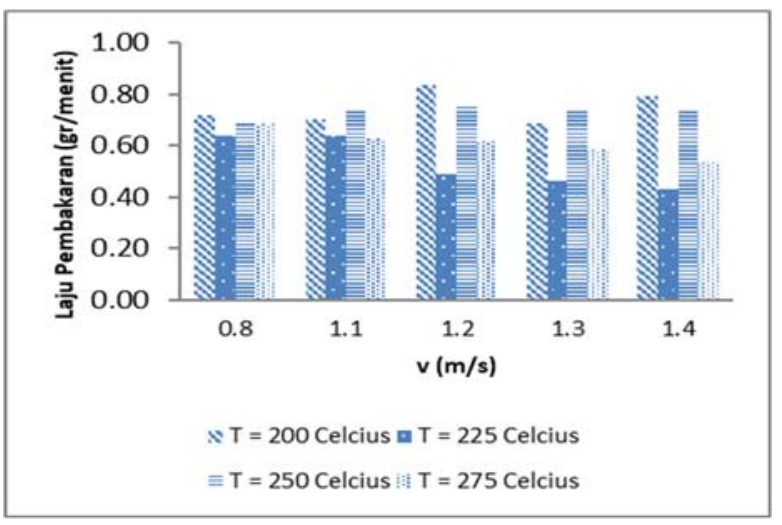

Gambar 2. Pengaruh kecepatan udara terhadap laju pembakaran briket untuk setiap variasi suhu karbonisasi
Grafik pada gambar 1 menunjukan pengaruh suhu karbonisasi terhadap laju pembakaran briket campuran sekam padi dan tongkol jagung pada suhu karbonisasi $200^{\circ} \mathrm{C}, 225^{\circ} \mathrm{C}, 250^{\circ} \mathrm{C}$ dan $275^{\circ} \mathrm{C}$. Secara keseluruhan, beberapa parameter yang berpengaruh terhadap laju pembakaran adalah kadar volatile matter dan fixed carbon. Sesuai dengan penelitian Rasyidi bahwa semakin besar kadar volatile matter maka briket akan mudah terbakar dan semakin besar fixed carbon maka panas yang dihasilkan briket saat pembakaran akan semakin besar dan berdampak pada laju pembakaran yang cepat. Briket dengan suhu karbonisasi $200^{\circ} \mathrm{C}$ memiliki kadar volatile matter yang tinggi yaitu $16,21 \%$ dan fixed carbon 49,6\% sehingga laju pembakarannya besar yaitu $0,68 \mathrm{gr} /$ menit begitupula pada briket dengan suhu karbonisasi $250^{\circ} \mathrm{C}$ memiliki fixed carbon $52,5 \%$ dengan laju pembakaran $0,69 \mathrm{gr} /$ menit. Sedangkan laju pembakaran optimum 0,46 gr/menit pada suhu karbonisasi $225^{\circ} \mathrm{C}$ dengan $\mathrm{v}=1,4 \mathrm{~m} / \mathrm{s}$.

Grafik pada gambar 2 menunjukan pengaruh kecepatan udara terhadap laju pembakaran briket bahwa semakin tinggi kecepatan udara maka temperatur pembakaran akan semakin rendah karena panas temperatur akan ikut terbuang seiring bertambahnya kecepatan udara yang dikenakan pada sampel. Temperatur akan berbanding lurus dengan massa, kenaikan temperatur dapat menyebabkan massa 
sampel akan lebih cepat habis dan berdampak pada lebih pendeknya waktu pembakaran sehingga laju pembakaran akan semakin besar. Dapat juga disebabkan oleh densitas briket, semakin besar densitas briket maka pori-pori briket akan lebih padat sehingga uap air dan laju pembakaran sulit untuk berdifusi yang berdampak pada lamanya waktu pembakaran briket. Laju pembakaran optimum 0,42 gr/menit dengan kecepatan udara $1,4 \mathrm{~m} / \mathrm{s}$ pada briket suhu karbonisasi $225^{\circ} \mathrm{C}$ karena memiliki laju pembakaran terkecil yang lebih efisien digunakan sebagai bahan bakar.

\section{Simpulan}

4.1. Semakin besar suhu karbonisasi dan kecepatan udara maka laju pembakaran akan semakin kecil karena semakin sedikitnya kadar volatile matter. Laju pembakaran optimum 0,46 gr/menit pada suhu karbonisasi $225^{\circ} \mathrm{C}$ dengan $\mathrm{v}=1,4$ $\mathrm{m} / \mathrm{s}$.

4.2. Semakin besar kecepatan udara maka laju pembakaran akan semakin kecil karena panas temperatur akan ikut terbuang dengan semakin besarnya kecepatan udara yang berdampak pada waktu pembakaran briket. Laju pembakaran optimum 0,42 gr/menit dengan kecepatan udara $1,4 \mathrm{~m} / \mathrm{s}$ pada briket suhu karbonisasi $225^{\circ} \mathrm{C}$.

\section{Referensi}

1. Purnomo, Hadi. (2013). Outlook Energi Indonesia (OEI). Jakarta: Dewan Energi Nasional.

2. Tajali, Arif. (2015). Panduan Penilaian Potensi Biomassa Sebagai Sumber Energi Alternatif. Jakarta: Panabulu Allience.

3. Daud, P. (2012). Karakteristik Termal Briket Arang Sekam Padi dengan Variasi Bahan Perekat. Jurnal Mekanikal, 3(2) : 286-293

4. Teguh, W.W., Asari., Ana, N., dan Elita, R. Bioenergi Berbasis Jagung dan Pemanfaatan Limbahnya. Balai Besar Pengembangan Mekanisasi Pertanian Serpong Badan Litbang Pertanian : Departemen Pertanian.

5. ASTM. (2014). Annual Book of ASTM Standard.

6. Rasyidi, F., Maiya,A.K., dan Sarah, F. (2011). Pengaruh Temperatur Karbonisasi dan Jumlah Bahan Perekat Pada Pembuatan Briket Bioarang dari Cangkang Kopi. Jurnal Teknik Kimia, 7(17): 32-39. 